\title{
EXILIO Y LEGALIDAD. AGENDA PARA UNA HISTORIA DE LAS LUCHAS JURÍDICO- NORMATIVAS DE LOS EXILIADOS ARGENTINOS DURANTE LA ÚLTIMA DICTADURA MILITAR ${ }^{1}$
}

\author{
Exile and legality. Agenda for a History of the legal- \\ normative struggles of the Argentine exiles during the \\ last military dictatorship
}

\author{
Silvina Jensen*
}

\begin{abstract}
RESUMEN
Este artículo se propone delinear una agenda de trabajo para problematizar las relaciones entre exilio y legalidad en la Argentina del "Proceso de Reorganización Nacional" (19761983).

Atento a que la historiografía argentina ha hecho foco en las dimensiones extrajudiciales, ilegales y clandestinas de la represión dictatorial y que el énfasis en la desaparición forzada de personas y el sistema concentracionario ha retrasado la interrogación de sus dimensiones institucionalizadas, legales y jurídicas, este trabajo se interroga sobre tres cuestiones en las que la denuncia de los exiliados se incardinó con las dimensiones jurídico-normativas del Estado terrorista, a saber: 1. Las razones
\end{abstract}

1 Este trabajo forma parte del PICT La investigación académica sobre el proceso de violencia política y la última dictadura militar en la Argentina. Perspectivas disciplinarias, configuraciones institucionales y articulaciones sociales y políticas, financiado por la Agencia Nacional de Promoción Científica y Tecnológica (ANPCyT) y el Fondo para la Investigación Científica y Tecnológica (FONCyT ) de Argentina.

* Doctora en Historia por la Universidad Autónoma de Barcelona. Profesora de grado y posgrado en la Universidad Nacional del Sur, Bahía Blanca e Investigadora del Consejo Nacional de Investigaciones Científicas y Técnicas (CONICET), Argentina. 
por las que la lucha antidictatorial de los exiliados atendió a la faz represivo-legal de la dictadura; 2. El lugar que ocupó en la denuncia de la legalidad autoritaria las diferentes formas del exilio producidos por el Estado terrorista; 3. Las formas que adoptó la apelación de los exiliados al Derecho (nacional e internacional) para obtener verdad sobre el destino de los "desaparecidos", conseguir la libertad de los detenidos sin causa ni proceso y para perseguir penalmente a los responsables de violaciones a los derechos humanos.

Palabras-clave: Exilio argentino; estrategia jurídica; Proceso de Reorganización Nacional.

\begin{abstract}
This article aims to outline an agenda to problematize the relationship between exile and legality in Argentina during the "National Reorganization Process". Since Argentina has made historiography focus on extrajudicial, illegal and clandestine dimensions of dictatorial repression and that emphasis on the forced disappearance of persons and the concentration camp system has delayed the question of their institutionalized, legal and legal dimensions, this paper asks about three issues on which the complaint was incardinated exiles with legal regulations terrorist-state dimensions, namely: 1 . The reasons why the antidictatorship struggle exiles attended the repressive-legal face of the dictatorship; 2 . The place occupied by the different forms of exile caused by the terrorist state in denouncing the authoritarian legality; 3 . The forms adopted by the appeal of exiles to law (national and international) for truth about the fate of the missing, to get the release of those detained without charges or trial and to prosecute those responsible for violations of human rights.
\end{abstract}

Keywords: Argentine exile; legal strategy; National Reorganization Process.

\title{
Consideraciones iniciales
}

En la notable expansión que en los últimos años ha evidenciado la historiografía argentina sobre los exilios políticos del 
pasado reciente ${ }^{2}$ se detectan aún importantes áreas de vacancia, sobre las que inciden los desafíos temático-problemáticos lanzados por el campo de estudios de la represión y la violencia política. ${ }^{3}$

$\mathrm{Si}$ en la historiografía exiliar se consolidan las investigaciones sobre las labores de denuncia y solidaridad encaradas por heterogéneas organizaciones de exiliados localizadas en diferentes geografías nacionales (Francia, México, España, Israel, Italia, Bélgica, Suecia, Brasil, entre otras), sobre las coyunturas de mayor efervescencia antidictatorial -Mundial de Fútbol 1978, visita a la Argentina de la Comisión Interamericana de Derechos Humanos (CIDH) de la Organización de Estados Americanos (OEA) 1979, guerra de Malvinas 1982) -, sobre los clivajes de tensión y conflicto en torno a la derrota, la guerra de Malvinas o las elecciones democráticas de $1983^{4}$, y sobre las reconfiguraciones identitarias operadas en la militancia exterior que mutó desde identificaciones político-partidarias ancladas en una matriz revolucionaria a otras de naturaleza más amplia y de perfil ético-humanitario; poco es lo que se ha realizado hasta el momento en orden a reconstruir las lecturas que los exiliados hicieron en la contemporaneidad de los hechos acerca del sistema represivo, su estructura operatoria, temporalidad, cifras regionales y modalidades (legales/ilegales, públicas/secretas, sistemáticas/irregulares, en su compleja articulación).

\footnotetext{
${ }^{2}$ Para un análisis del estado actual del campo de la Historia de los exilios argentinos de los años setenta, véase JENSEN, Silvina y LASTRA, Soledad. Para una nueva Historia de los exilios políticos de la Argentina reciente. En: JENSEN, Silvina y LASTRA, Soledad (edits.). Exilios: militancia y represión. Nuevas fuentes y nuevos abordajes de los destierros de la Argentina de los años setenta. La Plata: EDULP, 2014, pp. 5-39. JENSEN, Silvina. Desafíos actuales de la Historia de los exilios políticos en la Argentina. Diálogos con la Historia Reciente. Migraciones y Exilios. Madrid: Universidad Complutense de Madrid, nº 16, pp. 79-106, 2016 a.

${ }^{3}$ Para un análisis del estado actual del campo de la Historia de la represión, véase: ÁGUILA, Gabriela. Estudiar la represión: entre la historia, la memoria y la justicia. Problemas de conceptualización y método. En: FLIER, Patricia (comp.). Dilemas, apuestas y reflexiones teóricometodológicas para los abordajes en Historia Reciente. La Plata: Facultad de Humanidades y Ciencias de la Educación, UNLP, Estudios / Investigaciones, 52, 2014, pp. 20-55. ÁGUILA, Gabriela. La represión en la Argentina: modalidades, dinámicas regionales y efectos sociales. En: ÁGUILA, Gabriela y ALONSO, Luciano (comps.). Procesos represivos y actitudes sociales: entre la España franquista y las dictaduras del Cono Sur. Buenos Aires: Prometeo, 2013, pp. 97-121.

${ }^{4}$ En buena medida ésta fue la lógica de las compilaciones de: YANKELEVICH, Pablo. Represión y destierro. Itinerarios del exilio argentino. La Plata: Al Margen, 2004. YANKELEVICH, Pablo y JENSEN, Silvina. Exilios. Destinos y experiencias bajo la dictadura militar. Buenos Aires: Al Margen, 2007.
} 
¿Cuáles son las razones que podrían explicar esta laguna en la producción historiográfica argentina sobre los exilios políticos de los años setenta?

Más allá de que la agenda de temas de la historiografía exiliar reconoce puntos de confluencia con otras Historias de destierros nacionales (exilio republicano de la guerra civil española, exilios antifascistas italianos, exilios judíos de la Europa bajo los totalitarismos), algunas de estas ausencias pueden relacionarse con el tipo de fuentes privilegiadas por la primera historiografía exiliar, construida sobre la recuperación de memorias de los desplazados ${ }^{5}$ e inclinada a entender el exilio como experiencia política, pero sobre todo como experiencia humana fundada en el dolor. En esta primera producción, el tratamiento historiográfico del trabajo de denuncia parece duplicar los énfasis que los propios exiliados exponían en sus memorias, esto es, ha estado más atento a identificar sus objetivos (informar, denunciar, conseguir solidaridad), reconocer sus interlocutores (en el país de residencia o en la esfera pública internacional) y describir tareas específicas (campañas, manifestaciones, solicitadas, manifiestos, encuentros, publicaciones, etc.), que a historizar y contextualizar esa lucha que movida por la urgencia de salvar vidas, conocer el paradero de un "desaparecido" o conseguir la libertad o mejores condiciones de detención para un preso político, no fue ajena a profusos y complejos debates políticos, éticos, históricos y hasta jurídicos sobre las formas y alcances de la represión dictatorial.

Si en el último quinquenio la exploración de la denuncia exiliar evidencia un punto de inflexión y viene avanzado a paso sostenido desde la historización de las consignas de lucha, el reconocimiento de la diversidad de espacios de interlocución (locales, nacionales, regionales, internacionales y transnacionales) y el análisis

\footnotetext{
${ }^{5}$ El reconocimiento de la impronta del testimonio en la reconstrucción del último exilio no pretende subestimar que desde los primeros trabajos académicos se expresa un manejo amplio de materiales escritos provenientes de tres agentes fundamentales: las organizaciones de Derechos Humanos creadas por los exiliados en sus países de residencia y sus homólogas en Argentina; la amplia gama de organizaciones gubernamentales, no gubernamentales y humanitarias que fueron interlocutores de los exiliados en su tarea de denuncia (Amnesty Internacional, Comisión Internacional de Juristas, CIDH, y las organizaciones políticas o político-militares en el país y en el destierro.
} 
de las disputas protagonizadas por los exiliados en torno a la caracterización del régimen ("genocidio", "Estado terrorista", "fascismo dependiente", etc.); aún queda mucho por hacer en orden a quebrar con ciertos sentidos comunes. Quizás dos de los más extendidos sean que: 1 . la lucha exiliar estuvo incardinada desde los inicios del "Proceso de Reorganización Nacional" con el desvelamiento de la situación de los detenidos-desaparecidos; y 2. todo la acción colectiva exiliar se concentró en desnudar la naturaleza del dispositivo desaparecedor y de esa "forma novedosa de la muerte por causas políticas: su práctica clandestina". ${ }^{6}$

Este trabajo pretende incidir en un nicho poco explorado de la denuncia exiliar y en lo que considero problemas de la nueva agenda de los estudios de los exilios en diálogo con la Historia de la represión: los modos en que la acción colectiva de los desterrados argentinos atendió/cuestionó las dimensiones jurídico-normativas bajo el imperio del terrorismo de Estado. En este contexto, mi propuesta consiste en revisitar el archivo de materiales de denuncia del exilio $^{7}$ de cara a analizar no tanto cómo aparece tematizada la

${ }^{6}$ CRENZEL, Emilio. "Desaparición, memoria y conocimiento", en: La Historia Política del Nunca Más. La memoria de las desapariciones en la Argentina. Buenos Aires: Siglo XXI, 2008, pp. 27-51, p. 27.

${ }^{7}$ Cabe señalar que abordo el problema desde una escala transnacional y sin atender a la reconstrucción de la historia de las diferentes organizaciones de exiliados en contextos nacionales. Sin embargo, la sobrerrepresentación de materiales de la Comisión Argentina de Derechos Humanos (CADHU) merece ser explicada atendiendo al perfil de la institución y a la trayectoria de sus referentes en las más importantes de sus delegaciones (París, México, Madrid). La CADHU fue una organización humanitaria del exilio argentino que intervino en la lucha antidictatorial atendiendo preferentemente a su expertise jurídico-legal. Para un estudio pormenorizado de la CADHU y de algunas de las otras organizaciones cuyos materiales son utilizados en este trabajo (Comisión de Solidaridad de Familiares de Desaparecidos, Muertos y Presos Políticos (COSOFAM) -con sedes en diversos países de Europa, México e Israel y también Argentina - y Comité de Solidaridad con el Pueblo Argentino (COSPA) - surgido en México en febrero 1976 y con sedes en diferentes geografías de la diáspora -, véase: ALONSO, Luciano. ALONSO, L. Defensa de los Derechos Humanos y cultura política entre Argentina y Madrid, 1975-2005. Sevilla: Universidad Internacional de Andalucía, 2010. Tesis de Maestría. Disponible en: http://dspace.unia.es/bitstream/handle/10334/187/0068_Alonso.pdf?sequence=1 MIRA DELLIZOTTI, GUILLERMO. La singularidad del exilio argentino en Madrid: entre las respuestas a la represión de los '70 s y la interpelación a la Argentina posdictatorial. En: YANKELEVICH, Pablo (comp.). Represión y destierro. Itinerarios del exilio argentino. La Plata: Al Margen, 2004, pp. 87112.; FRANCO, Marina. El exilio. Argentinos en Francia durante la dictadura. Buenos Aires: Siglo XXI Editores Argentina, 2008. YANKELEVICH, Pablo. Ráfagas de un exilio. Argentinos en México, 1974-1983. México: FCE, 2010. JENSEN, Silvina. El descubrimiento de los derechos humanos en el exilio español. Los derroteros de COSOFAM Barcelona en la lucha antidictatorial 
política represiva del Estado en su modalidad más extendida y más aberrante - la desaparición forzada de personas y los centros clandestinos de detención -, sino para reconocer cómo los desterrados dieron cuenta de las paradójicas ${ }^{8}$ relaciones entre terrorismo de Estado y legalidad.

El artículo se organiza en tres apartados que pretenden incidir sobre: 1. Las razones por las que la lucha antidictatorial de los exiliados atendió a la faz represivo-legal de la dictadura; 2. El lugar que ocupó en la denuncia de la legalidad autoritaria las diferentes formas institucionalizadas de exilio; 3. Las formas que adoptó la apelación de los exiliados al Derecho (nacional e internacional) para obtener verdad sobre el destino de los desaparecidos, conseguir la libertad de los detenidos sin causa ni proceso y para perseguir penalmente a los responsables de violaciones a los derechos humanos.

\section{¿Para qué denunciar la legalidad represiva?}

Si ya durante el primer año de la dictadura, los exiliados percibieron la dificultad que enfrentaban a la hora de denunciar a un régimen que operaba punitivamente en forma clandestina, "por los cauces de una guerra sucia y despiadada contra el conjunto del pueblo argentino,",; no menos dilemas enfrentaron a hora de decidir si valía la pena y si tenía algún efecto en términos de cerco

(1978-1983). En: KOTLER, Rubén (coord.). En el país del sí me acuerdo: los orígenes nacionales y transnacionales del movimiento de derechos humanos en Argentina: de la dictadura a la transición. Buenos Aires: Imago Mundi, 2014, pp. 157-186.

${ }^{8}$ Victoria Crespo afirmaba que "una de las paradojas de la dictadura instaurada [en Argentina] en 1976 es que simultáneamente creó inusitados espacios de violencia y ausencia del Estado de derecho y uno de los órdenes más legalistas de nuestra historia moderna. Esta incongruente relación entre legalidad y dictadura nos conduce a uno de los problemas fundamentales del pensamiento político contemporáneo. En palabras de Agamben: 'El estado de excepción aparece como la forma legal de lo que no puede tener forma legal"'. CRESPO, Victoria. Legalidad y dictadura. En: LIDA, Clara et al. Argentina 1976. Estudios en torno al golpe de Estado. México: El Colegio de México, 2007, pp. 165-186, p. 165.

9 "Informe n²: Hechos generales hasta el 7 de julio de 1976", Madrid. Colección CADHU, Caja 29, Archivo Nacional de la Memoria, Buenos Aires. 
internacional y multiplicación de la solidaridad, atender a las estructuras jurídicas represivas activadas o profundizadas por los gobiernos del "Proceso de Reorganización Nacional" en orden a la eliminación del "enemigo subversivo".

El primer desafío que asumieron las agrupaciones del exilio fue mostrar que mientras la Junta afirmaba protagonizar un "proceso de reorganización nacional" en base al "accionar de las instituciones constitucionales revitalizadas" y a la "vigencia plena del orden jurídico y social", estaba operando la más completa "cesación del Estado de derecho"10, en tanto la Constitución Nacional era apenas una "referencia formal"11 y todos los derechos amparados por los instrumentos internacionales del sistema humanitario de los que Argentina era signataria (Declaración Universal de Derechos Humanos de 1948, Protocolos Adicionales, Convenciones Internacionales de Ginebra, Convenciones 87 y 89 de la Organización Internacional del Trabajo, Cartas delas Naciones Unidas (NNUU) y de la OEA, entre otros) eran vulnerados en forma cotidiana y sistemática. ${ }^{12}$ Asimismo, los exiliados denunciaron que más allá de la difícil cohabitación entre una Constitución vigente, pero subordinada y reformada ${ }^{13}$, y una pseudo-juridicidad represiva puesta en marcha en los días posteriores al golpe de cara al "adecuado cumplimiento de los objetivos políticos, económicos y sociales"; la Junta ponía en entredicho en la práctica esa manifiesta "vocación legalista"14 procediendo punitivamente de modo extrajudicial, clandestino $\mathrm{y}$ extremadamente violento (muertes, desapariciones).

\footnotetext{
${ }^{10}$ CADHU. Argentina: Proceso al Genocidio. Buenos Aires: Colihue, 2014, p. 49.

${ }^{11}$ Tribunal Permanente de los Pueblos. "Resolución sobre la situación de los Derechos Humanos en la Argentina". Ginebra, 3-4/5/1980. Colección CADHU, Caja 19: Informes y declaraciones, Archivo Nacional de la Memoria, Buenos Aires.

${ }^{12}$ En Argentina Proceso al Genocidio, la CADHU enumeraba los derechos conculcados por la Junta militar en el marco jurídico nacional e internacional, a saber: a la vida, la libertad y seguridad individuales, prohibición de la tortura, detención arbitraria y destierro, al debido proceso, al asilo, a la soberanía popular, libertad sindical, opinión y expresión, reunión y asociación y derechos culturales y sociales. CADHU, ob cit, 2014, pp. 173-174.

${ }^{13}$ GROISMAN, Enrique. Utilización del derecho en la dictadura de la Junta Militar. Espacios de crítica y producción, Buenos Aires: UBA, n 27/28, pp. 10-19, octubre-noviembre de 2001, p. 10.

${ }^{14}$ CADHU, ob cit, 2014, p.51.
} 
Mientras los militares generaban esta "avalancha legisferante" ${ }^{\prime 5}$, los exiliados discutían acerca del verdadero alcance de la normativa represiva y en tal sentido, acerca de la necesidad o no de denunciarla. Sin duda existía un amplio acuerdo acerca de que esa "fiebre" represivo-legal ${ }^{16}$ era funcional a la necesidad de "ocultar la violencia que los militares consideraban necesaria para reordenar la sociedad, dotando a sus acciones punitivas de un "ropaje de legitimidad". Como señalaba el Comité de Solidaridad con el Pueblo Argentino (COSPA) de México, "esa legalidad opera como el instrumento que ordena y racionaliza la violencia"; si en algún sentido sirve para fijar "ciertas reglas de juego", ante todo "este ordenamiento sirve como filtro disimulador de la violencia". ${ }^{17}$

¿Pero ese carácter de artilugio leguleyo, anulaba su eficacia y su incidencia en la realidad social?; ¿la denuncia del alcance de la pseudo-institucionalidad debía limitarse a exponer que era una máscara, una excrecencia, un adorno, una cortina de humo, una ficción diabólica?; o ¿se imponía explicitar, como dirá Victoria $\mathrm{Crespo}^{18}$, que esa "dimensión jurídica" no sólo desvelaba la "lógica de la dictadura" y sus objetivos últimos, sino que trazaba una línea recta con aquellos aspectos que hacían a la singularidad represiva de la Argentina en el contexto de la región: la metodología de la desaparición forzada de personas, el accionar de los grupos de tareas y la existencia de centros clandestinos de detención. ${ }^{19}$

De hecho, los exiliados evaluaron que la denuncia de la legislación represiva tenía un triple valor. En primer lugar, porque iluminaba la auténtica "ideología de la Junta" y su "política de dominación", en particular "su contenido antiobrero y opresor" 20 . En segundo lugar, porque mostraba el propósito de la Junta de producir

15 CADHU. "La ruptura de la legalidad constitucional en Argentina, 1983". Colección CADHU, Caja 28: Cuadernillos/Volantes y Catálogos, Archivo Nacional de la Memoria, Buenos Aires.

${ }^{16}$ CADHU, ob cit, 2014, p.51.

${ }^{17}$ Comité de Solidaridad con el Pueblo Argentino (COSPA). "Documento de denuncia de la situación de los derechos humanos en Argentina". Sin lugar, circa 1979/1980, Archivo Nacional de la Memoria, Buenos Aires.

${ }^{18}$ CRESPO, ob cit, p. 168.

${ }^{19}$ PEREIRA, Anthony. Ditadura e repressao. O autoritarismo e o estado de direito no Brasil, no Chile e na Argentina. Sao Paulo: Paz e Terra, 2010, p. 200.

${ }^{20}$ CADHU, ob cit, 2014, p.139. 
comportamientos sociales en orden a intimidar, aterrorizar y por fin desarticular toda "forma de oposición, resistencia o simple desobediencia" por "imposición de graves y desproporcionadas penas" 21 . La CADHU denunciaba que esas "normas de excepción" formaban parte de los instrumentos de "autoexplicitación" y naturalización del terror ${ }^{22}$ y de producción de conductas sociales disciplinadas, cómplices ${ }^{23}$ o convencidas de la legitimidad de la represión. ${ }^{24} \mathrm{Y}$, en tercer lugar, porque desvelaba la política exterior del gobierno castrense en aras de retardar o diluir las condenas internacionales sobre la situación de los Derechos Humanos en el país. Como denunciaba Emilio Mignone en el Coloquio de París sobre Desaparición Forzada de Personas (enero de 1981) ${ }^{25}$, "actuar con dureza pero dentro de un sistema sancionado legalmente, fundado en el funcionamiento de tribunales militares ordinarios en jurisdicción ampliada y la aplicación en determinados casos de medidas extremas", fue parte de una estrategia cuidadosamente diseñada para evitar "influencias y presiones externas" 26 - como las sufridas por Chile - y para gestionar en forma racional los desafíos planteados por los actores de la esfera internacional (gobiernos, organizaciones no gubernamentales, foros internacionales). Como explicaba la CADHU

${ }^{21}$ CADHU, ob cit, 2014, p. 49.

${ }^{22}$ En el mediodía de la dictadura, la CADHU denunciaba que "la legislación será un marco que determinará algunas reglas de juego, pero fundamentalmente este ordenamiento servirá como filtro disimulador de la violencia, y para que a ésta se la pueda considera como algo "natural". Obviamente que estamos ante una violencia sesgada dirigida en contra de quienes osaron cuestionar la "sociedad occidental y cristiana". CADHU. "Documento de denuncia", spi, circa 1980/1981. Colección CADHU, Caja 20: Informes y declaraciones, Archivo Nacional de la Memoria, Buenos Aires.

${ }^{23}$ La problematización de las formas represivas legales permitió a la CADHU denunciar a la "cohorte de "juristas" que encontraban justificación "constitucional" a las más aberrantes monstruosidades jurídicas y que cubrían afanosamente a través de diversas y complicadas "leyes", la necesidad de "legalizar" la represión y la persecución política e ideológica" (CADHU, op cit, 2014, p. 51). En esa línea, la denuncia del aparato represivo legal se convirtió en un medio indirecto para desnudar responsabilidades corporativas y sociales con el terrorismo de Estado.

${ }^{24}$ CADHU. "Documento de denuncia", spi, circa 1980/1981.

${ }^{25}$ Entre los impulsores del Coloquio aparecían la CADHU y en concreto el abogado Rodolfo Mattarollo, referente de la sede parisina.

${ }^{26}$ MIGNONE, Emilio (Centro de Estudios Legales y Sociales). "El caso argentino: desapariciones forzadas como instrumento básico y generalizado de una política". Coloquio Internacional "La Política de desaparición forzada de personas", Senado de la República Francesa, 31/2-1/2/1981. En: AMORÓS, Mario (coord.) Argentina en el Archivo de IEPALA (1976-1983). Madrid: IEPALA, 2011, p. 315. 
en 1977, la "Junta militar necesita vitalmente ocultar a la opinión pública nacional y sobre todo mundial, el número de prisioneros políticos para 'cuidar' su ya deteriorada imagen internacional y para intentar diferenciarse de las dictaduras militares chilena y uruguaya, ya definitivamente condenadas por los actos de verdadero genocidio cometidos contra sus pueblos"27.

Pero ¿qué nuevo valor asumió para los exiliados la denuncia de esa "institucionalidad del terror" 28 cuando en el contexto de la visita de la CIDH a la Argentina los militares usaron la ley ${ }^{29}$ con la pretensión de pasar al terreno de lo público y de lo institucional aquel "genocidio" 30 que venían perpetrando en la clandestinidad y a través de procedimientos extrajudiciales y absolutamente violentos?

En este contexto, los exiliados percibieron que la Junta militar pretendía avanzar hacia el borramiento de los crímenes clandestinos, diluyendo las responsabilidades penales de los perpetradores y cercenando a los familiares de las víctimas cualquier posibilidad de justicia futura. Desde el exilio se planteó que las leyes sobre "ausentes para siempre" ${ }^{31}$ respondían a una doble estrategia

${ }^{27}$ CADHU, ob cit, 2014, p. 69

${ }^{28}$ CADHU. "La ruptura de la legalidad constitucional en Argentina, 1983"....

${ }^{29}$ Me refiero a los decretos-leyes 22.062 (5/9/1979) y 22.068 (12//9/1979) que regulaban por una parte el tema de "jubilaciones, pensiones y prestaciones no contributivas" de los "ausentes del lugar de su residencia o domicilio"; y por la otra, habilitaban por vía express a certificar el fallecimiento presunto de los "desaparecidos". La Ley 22.062 pretendía "regularizar la situación que aflige a un número de familias argentinas, motivada por la ausencia prolongada y el destino de algunos de sus integrantes, como consecuencia de los graves eventos que afrontó nuestro país en el pasado reciente" (Boletín Oficial de la República Argentina (BORA), 12/9/1979). Como explicaba la $\mathrm{CIDH}$, esta ley establecía que transcurrido un año de ausencia de la persona, se "facultaba a quienes tuvieran un derecho reconocido por las leyes nacionales de jubilaciones y pensiones o de prestaciones no contributivas, subordinado a la muerte de esa persona, a ejercerlo en la forma prescrita por la presente ley" (CIDH, 1980). La Ley 22.068 establecía que "podría declararse el fallecimiento presunto de la persona cuya desaparición del lugar de su domicilio o residencia [...] hubiese sido fehacientemente denunciada entre el 6 de noviembre de 1974, fecha de declaración del Estado de sitio [...] y la fecha de la presente ley" (CIDH, 1980).

${ }^{30}$ En el contexto de la visita de la CIDH a la Argentina (6-20/9/1979) y mientras los militares aprobaban los decretos-leyes que pretendían dar una respuesta al "problema de los desaparecido"s, desde diversas comunidades del exilio, por caso España, se agitó la consigna "Contra la legalización del genocidio". Véase por ejemplo: Centro Argentino de Madrid. Contra la legalización del genocidio. Presencia Argentina. Periódico del Centro Argentino de Madrid, año 1, n 1 , octubre 1979 , p. 2.

31 "Ausentes" fue la calificación incluida en las leyes para referirse a los "desaparecidos" y fue la expresión utilizada en julio de 1979 por el general Roberto Viola en declaraciones ante la prensa española. En la coyuntura de aprobación de las leyes, el Ministro del 
exculpatoria dirigida hacia la opinión pública nacional e internacional. Como sentenciaba el Centro Argentino de Madrid, las leyes fueron el último recurso para "legitimar el genocidio mediante la declaración judicial de fallecimiento de los desaparecidos". ${ }^{32}$ Como declaraban los exiliados ante la prensa internacional, las leyes eran una continuidad de la política oficial de silencio y negación que tenía su clímax en esta "cruel farsa legal",33, fruto del "cinismo de la dictadura" y del "ingenio de sus juristas" ${ }^{34}$. Un intento de formatear por medio de un decreto-ley un "pasado a la carta"35.

En esta coyuntura, la denuncia de la nueva "aberración jurídica" llevó al exilio a clarificar sus implicancias presentes y futuras. ${ }^{36}$ Presentes porque facultaba al Poder Judicial a dar "oficialmente por muertos y de manera unilateral a los "desaparecidos"37, y todo esto, como señalaba la CIDH, sin que el Estado movilizara sus recursos para identificar y castigar a los responsables de las desapariciones, para esclarecer las circunstancias de los secuestros o para localizar los lugares donde pudieran haber

Interior, general Albano Harguindeguy, confirmó que en Argentina "no había desaparecidos, sino muertos no registrados" y aclaró que en el país no había "más presos políticos que los reconocidos oficialmente". El reconocimiento de las "desapariciones", un cambio de postura del gobierno argentino. El País, Madrid, 25/8/1979.

32 Centro Argentino de Madrid. La OEA y el terrorismo de Estado. Presencia Argentina. Periódico del Centro Argentino de Madrid, año 1, nº 1, octubre 1979, p. 6.

${ }^{33}$ Dos años después de la promulgación de las leyes, la CADHU declaraba ante las NNUU que "el propio Estado dictatorial ha tratado de dar amparo normativo a la acción del Estado terrorista y clandestino, la otra faceta de este modelo de Estado de excepción, arquetípico de los regímenes implantados en los países del Cono Sur de América Latina. La prueba de ello lo constituye el dictado de la ley $\mathrm{n}^{\circ} 22.068$, del 12 de septiembre de 1979 , en virtud de la cual tanto el Estado como un pariente pueden declarar muerta a cualquier persona "desaparecida" durante los cinco años previos, sin que el propio Estado arbitre normas investigativas sobre las circunstancias de modo y lugar en que se produjeron esos presuntivos fallecimientos, intentando así legalizar el crimen de las víctimas sujeto de tal declaración". CADHU. La violación sistemática de los Derechos Humanos persiste en la República Argentina. En: AMORÓS, Mario (coord.) Argentina en el Archivo de IEPALA (1976-1983). Madrid: IEPALA, 2011, p. 415.

${ }^{34}$ Centro Argentino de Madrid. La OEA y el terrorismo de Estado, ob cit., p. 6.

35 Protestas argentinas por "muerte" de desaparecidos. El Periódico de Catalunya, Barcelona, 1/9/1979.

${ }^{36}$ La revista Testimonio Latinoamericano de Barcelona - vocera del peronismo en el exilio - calificaba a las leyes como un "intento de "solución final" del problema de los desaparecidos” y reflexionaba sobre su impacto en la denuncia exiliar: "¿Podían haber pergeñado los amanuenses de la Junta un engendro jurídico tan infortunado y más idóneo para levantar un huracán de protestas?" (año I, nº 1, marzo/abril 1980, p. 6).

${ }^{37}$ Salvemos a los desaparecidos en Argentina. Tele/éXpres. Barcelona, 28/8/1979. 
sido inhumados aquellos detenidos que estuvieran muertos ${ }^{38}$. Futuras porque como denunciaban la Comisión de Solidaridad de Familiares de Muertos, Presos Políticos y Desaparecidos de Barcelona (COSOFAM) y la Casa Argentina de Catalunya, la Junta estaba desarrollando un "burdo intento por lavarse las manos ante los por lo menos quince mil detenidos-desaparecidos que el terrorismo de Estado torturó y asesinó ${ }^{39}$, buscando, como denunciaba la CIDH, incapacitar a los familiares para proseguir acciones penales futuras o incluso para recurrir al habeas corpus con el fin de investigar la desaparición ${ }^{40}$.

En este contexto, el exilio manifestó que el pasado no pasaría por medio de decretos-leyes. Frente a la estrategia militar de cimentar un "doble cementerio" ("muertos reales y legales"41), los exiliados levantaron una bandera con cuatro consignas fundamentales: "aparición con vida de todos los desaparecidos", "derogación de toda norma jurídica que intentara legalizar el genocidio", "liberación de todos los presos políticos" y "plena vigencia de los derechos humanos".

En definitiva, la sanción de estas leyes pareció confirmar a los exiliados la utilidad de una denuncia integral de la represión. La normativa sobre los "ausentes para siempre" daba cuenta de que cuando los militares no pudieron seguir administrando las desapariciones en el terreno de lo clandestino, el secreto y el silencio, las pasaron al aparato legal público, convertidas en meras certificaciones oficiales de muerte. De esa peculiar modalidad de muerte violenta, que no acreditaba cadáver, responsables, ni circunstancias.

\footnotetext{
${ }^{38}$ CIDH. Informe sobre la situación de los Derechos Humanos en Argentina. Washington: O.E.A, 1980. Disponible en: http://desaparecidos.org/nuncamas/web/document/internac/cidh 79/03b.htm\#F.Las Leyes sobre Desaparecidos

${ }^{39}$ Campaña de solidaridad con presos y desaparecidos en la Argentina. El Periódico de Catalunya, 9/7/1980

40 Sobre la opinión de la $\mathrm{CIDH}$ sobre las leyes, véase: http://desaparecidos.org/nuncamas/web/document/internac/cidh79/03b.htm\#F.Las Leyes sobre Desaparecidos

${ }^{41}$ Palomares, Alfonso. Argentina: muertos reales, legales. El Periódico de Catalunya, Barcelona, 8/9/1979

${ }^{42}$ Centro Argentino de Madrid. Contra la legalización del genocidio, ob cit, p.2.
} 


\section{¿En qué medida la denuncia de la legalidad represiva dictatorial comprometió modalidades de exilio?}

Aunque una de las singularidades del exilio dictatorial radica en que el grueso de las salidas no fueron sancionadas por procedimientos jurídico-legales, sino determinadas por el contexto político y asumieron la forma de huidas y fugas ${ }^{43}$-consecuencias directas o indirectas de la represión estatal o paraestatal -; la dictadura argentina también aplicó penas de destierro y de expulsión/deportación a individuos y conjuntos específicos de la población.

Curiosamente, dos modalidades de exilio legal/normativizado resultaron foco de atención desde momentos tempranos de la acción colectiva de los desterrados. Por un lado, la situación que vivían asilados y refugiados latinoamericanos residentes en el país; y por el otro, la situación de los presos políticos que pretendían utilizar el derecho constitucional de "opción" para salir del país. ${ }^{44}$

¿Por qué hacer foco en esas modalidades de exilio para denunciar la pseudojuricidad represiva?, ¿En qué medida permitían mostrar la verdadera matriz punitiva dictatorial que no se agotaba en sus reglas formales y públicas, que eran sistemáticamente flexibilizadas y rebasadas en los hechos?, ¿De qué forma lo vivido

${ }^{43}$ Considero que la modalidad prioritaria de concretar el exilio en Argentina no fue ajena a su matriz represiva dominante: la desaparición forzada y el centro clandestino de detención. La mayoritaria modalidad de exilio-huida asume de hecho algunas marcas propias del universo de lo represivo extrajudicial y clandestino: fueron salidas informales, más o menos precipitadas, configuradas por el miedo, viajes subrepticios, secretos, silenciosos y silenciados, desfigurados por el Estado y autonegados, y que por regla general carecieron de impronta normativa o burocrática. Estos exilios-fuga distinguen la experiencia de expatriación argentina de la chilena donde los decretos de expulsión, los extrañamientos públicos y las prohibiciones legales de retorno - aún tampoco siendo las modalidades más numerosas - han permitido afirmar de forma más clara y menos controvertida (tanto en el debate público como en la academia) que el exilio fue una práctica represiva contemplada por el régimen pinochetista.

${ }^{44} \mathrm{La}$ "opción" es un derecho contemplado por la Constitución Nacional (art. 23) que establece que cuando por determinado clima político o estado de conmoción interior, el presidente declara el Estado de sitio, el Ejecutivo tiene la prerrogativa de trasladar a detenidos considerados peligrosos dentro del territorio del país y eventualmente concederles el beneficio de salir del mismo. 
por asilados y refugiados latinoamericanos y presos políticosopcionados expresaba el nítido "concubinato entre la legalidad dictatorial y la violencia clandestina", conceptos que como afirmaba la CADHU, lejos de ser "antagónicos", se "complementaban entre sí retroalimentándose" en la dinámica punitiva dictatorial? ${ }^{45}$.

En marzo de 1977 y como ampliación de sus primeras denuncias de alcance internacional ante el Congreso de los EEUU ${ }^{46}$, la CADHU publicaba en Madrid Argentina: Proceso al genocidio. La prensa española lo consideró el primer retrato de la "tragedia" que vivía la Argentina y "uno de los golpes más contundentes en el plano de la difusión internacional acerca de la política criminal" del gobierno militar surgido del "golpe de Estado más fascistizante que recuerde la historia del país sudamericano" (El País, 10/4/1977). En ese documento, la CADHU confirmaba que si Argentina había sido lugar de amparo y protección para las "víctimas de la persecución política y social" que habían salido de sus países tras los sucesivos golpes en Bolivia (Hugo Banzer), Uruguay (Juan María Bordaberry) y Chile (Augusto Pinochet) ${ }^{47}$; desde el verano de 1974 y la muerte del presidente Juan Domingo Perón (1/7/1974) y sobre todo desde 1975, se había convertido en una trampa para esos miles de ciudadanos de

${ }^{45}$ CADHU. "Documento de denuncia", spi, circa 1980/1981.

${ }^{46}$ El 28 y 29 de septiembre de 1976, el Subcomité de Asuntos Hemisféricos de la Cámara de Representantes norteamericana escuchaba el testimonio de dos abogados argentinos perseguidos por las FFAA y de Seguridad, exiliados e integrantes de CADHU. Gustavo Roca y Lucio Garzón Maceda denunciaron la situación de los Derechos Humanos en su país de origen y dieron cuenta de la persecución que estaban sufriendo refugiados y asilados latinoamericanos. Garzón Maceda recuerda que las preguntas de los diputados estadounidenses versaron principalmente sobre el número de refugiados provenientes de países vecinos residentes en Argentina (aproximadamente 15.000, de los cuales entre 2000 y 3000 estarían pidiendo asilo en terceros países); la veracidad de las noticias sobre secuestros e intimidación de los refugiados alojados en hoteles especialmente acondicionados para ellos; y sobre la actuación conjunta de policías y fuerzas militares de Argentina, Chile, y Uruguay en orden a la represión de exiliados chilenos, uruguayos y bolivianos residentes en el país. Véase: GARZÓN MACEDA, Lucio. Testimonio. La primera derrota de la dictadura en el campo internacional. En: QUIROGA, Hugo y TCACH, César (comps.), Argentina 1976-2006. Entre la sombra de la dictadura y el futuro de la democracia. Rosario: UNL-Homo Sapiens, 2006, pp. 233-270.

${ }^{47} \mathrm{La}$ CADHU incluía también la situación de paraguayos y brasileños que habían iniciado tempranamente un "verdadero éxodo hacia Argentina", como consecuencia de la instalación de dictaduras, ahora ya consolidadas (CADHU, 2014, p. 94). 
países de la región instalados como estudiantes, asilados, refugiados, inmigrantes con residencia permanente o transitoria. ${ }^{48}$

Para la CADHU, la situación de refugiados y asilados latinoamericanos ${ }^{49}$ revelaba en forma nítida la verdadera naturaleza del régimen militar argentino. El análisis de la operatoria represiva (prácticas de inteligencia, persecución, detención ilegal, tortura, muerte, desaparición, expulsión, repatriación forzada, transferencias ilegales y accionar extraterritorial), de los comportamientos que punía, de la identidad de los perpetradores y del cuadro de derechos que conculcaba ${ }^{50}$, mostraba una lógica común de actuación del Estado terrorista argentino sobre uruguayos, chilenos, paraguayos, bolivianos, brasileros o peruanos residentes en el país y sobre su

${ }^{48}$ En un documento elaborado en junio de 1978 por juristas uruguayos y firmado por Leandro Despouy -, integrante del Comité Directivo del Secretariado Internacional de Juristas por la Amnistía en Uruguay -, se reconocían varias categorías de refugiados en la Argentina: 1. personas con asilo político formalmente concedido por el gobierno (Zelmar Michelini y Enrique Erro); 2. personas beneficiadas por el procedimiento simplificado de tramitación de residencia permanente para extranjeros llegados antes del 1/1/1974; 3. personas que gozaban de protección y ayuda del Alto Comisionado de las Naciones Unidades para los Refugiados (ACNUR); 4. refugiados de hecho, es decir, los que buscaban un permiso de radicación pero no estaban registrados como exiliados aunque su salida del país de origen obedeció a motivos políticos; y 5 . personas para quienes Argentina era un segundo país de refugio (muchos de los latinoamericanos que procedían de Chile. Archivo CEDINCI.

${ }^{49}$ La situación de paraguayos y chilenos residentes (exiliados políticos, militantes en tránsito desplegando política extraterritorial, antiguos inmigrantes devenidos en perseguidos políticos o en actores políticos y asilados territoriales) en Argentina viene despertando un creciente interés historiográfico. Pueden verse entre otros: HALPERN, Gerardo. Etnicidad, inmigración y política. Representaciones y cultura política de exiliados paraguayos en Argentina. Buenos Aires: Prometeo Libros, 2009. AZCONEGUI (2014), LASTRA, Soledad y PEÑALOZA, Carla. Asilos en dictaduras: chilenos en la embajada argentina. Perfiles Latinoamericanos. México: FLACSO, México, 24 (48), pp. 83-109, 2016. Disponible en: http://perfilesla.flacso.edu.mx/index.php/perfilesla/article/view/724/667, CASOLA, Natalia. Continuidades y rupturas en la actividad de la DIPBA sobre los exiliados chilenos (1973-1990). Algunas notas sobre la función de la inteligencia estatal en el pasado reciente. En: II Jornadas de Trabajo de la Red de Estudios sobre Represión y Violencia Política. Buenos Aires: IDAES, UNSAM, abril 2016. Inédito.

${ }^{50}$ Por referencia a instrumentos jurídicos humanitarios internacionales (Declaración Universal de Derechos Humanos (art. 8, 14, 15), la Convención de Ginebra (art. 31, 32, 33), la Declaración sobre Asilo Territorial de las NNUU (1967), el Tratado de Derecho Penal Internacional de Montevideo (1889), la Convención sobre extradición de Montevideo (1933) y Declaración Americana de los Derechos y Deberes del Hombre (1948)), la CADHU denunciaba la vulneración de los derechos de circular libremente y elegir su residencia en el territorio de un Estado; salir de cualquier país incluso del propio y regresar; buscar asilo y disfrutar de él en cualquier país; no ser expulsado o devuelto a un territorio donde la vida o libertad peligre por causa de raza, religión, nacionalidad, pertenencia a determinado grupo social o por opiniones políticas; y no ser detenido o desterrado en forma arbitraria. 
población nativa. Lógica que no se reducía al uso de los resortes represivos legales, sino al sostenido incremento de modalidades clandestinas y procedimientos extrajudiciales que fueron configurándose desde antes del golpe y que combinados tras el quiebre institucional con la rigurosa "legislación de facto" de la Junta militar, terminaron por imponer un tipo de Estado que, a juicio de la CADHU, modificó "la relación entre el aparato represivo y los aparatos ideológicos", eliminando los límites a la "antijuridicidad" que un Estado de derecho se obliga a respetar. ${ }^{51}$

En Proceso al genocidio, la CADHU asumía el diagnóstico de otras organizaciones humanitarias como Amnistía Internacional $(\mathrm{AI})^{52}$ y la Comisión Internacional de Juristas (CIJ) y denunciaba que las restricciones, la intimidación, los ataques y la persecución directa sobre la población de origen extranjero residente en la Argentina y en particular sobre los fugitivos de otros países de la región, no se había iniciado con el golpe de Estado del 24 de marzo de 1976. Desde su perspectiva, el verano de 1974 fue el punto de arranque de la coordinación policial y militar entre los países de la región en orden al intercambio de información y para la cooperación represiva política e ideológica sobre el universo de los refugiados y asilados. En este contexto, la CADHU señalaba que "el gobierno de la Junta Militar no innovó al respecto. Siguió exactamente la misma política, con la diferencia de que extendió y profundizó la empresa persecutoria". ${ }^{53}$ La sucesión de eventos represivos durante el primer año de gobierno militar incluía, a juicio de la CADHU, desde la intensificación de los mecanismos de control estatal, imponiendo a los asilados la obligación de actualizar la información acerca de sus domicilios y renovar mensualmente los permisos de permanencia; el secuestro de exiliados notables como el general Juan José Torres - ex presidente

\footnotetext{
${ }^{51}$ Duhalde, Eduardo, El terrorismo de Estado y la Doctrina de la Seguridad Nacional en la República Argentina, sin fecha (presumiblemente finales de 1977). Archivo Nacional de la Memoria. Colección CADHU, Caja 28: Cuadernillos/Volantes y Catálogos.

${ }^{52}$ En su informe de la vista al país de diciembre de 1976, AI ratificaba que desde el gobierno de Isabel Perón la seguridad de los refugiados latinoamericanos se fue deteriorando. En forma progresiva, "ser extranjero, terminó por ser equivalente de ser "subversivo" y los refugiados chilenos se convirtieron en el blanco privilegiado de amenazas, intimidación y muerte de grupos paraestatales. Amnistía Internacional. Informe de la misión de AI a la República Argentina, 5 7/11/1976. Barcelona: Blume, 1977, p. 56.

${ }^{53}$ CADHU, ob cit, 2014, p. 97.
} 
de Bolivia (mayo 1976), cuya detención fue negada por el gobierno y cuyo cadáver apareció pocos días después acribillado a balazos -, o el de los legisladores uruguayos, Zelmar Michelini y Héctor Gutiérrez Ruiz (mayo 1976) - arrancados violentamente de sus domicilios, torturados y asesinados por militares argentinos en connivencia con sus pares uruguayos -; hasta los ataques a los hoteles Hilton y del Pino de la ciudad de Buenos Aires donde estaban alojados 110 refugiados (y sus familiares) bajo protección de NNUU; y también el asalto a las oficinas de la Comisión Católica Argentina de Inmigración (9/6/1976) para consumar el robo de más de 2000 legajos de refugiados.

La otra modalidad legal de exilio que ocupó el interés de los expatriados fue la "opción". Modalidad compleja que tal como la recogía el texto de la Constitución argentina de 1853 no era una pena, sino un derecho ${ }^{54}$ que durante la vigencia del Estado de sitio y en suspensión de las garantías constitucionales, debía operar como único reaseguro para las personas detenidas sin causa ni proceso y como límite a los nuevos poderes que en esas circunstancias concentraba el Ejecutivo. Sin embargo, la Junta militar argentina ${ }^{55}$ actuó primero suspendiendo la "opción" y renovando esa suspensión, aplicando esa suspensión de forma retroactiva y luego reglamentando su aplicación y haciendo un uso arbitrario y discrecional que limitó ese derecho a

\footnotetext{
${ }^{54}$ Recordemos que la Constitución de 1853 fue redactada sobre la base de las ideas de un emigrado político del gobierno de Juan Manuel de Rosas (1835-1852), Juan B. Alberdi. Como explican SZNADJER y RONIGER (2013), en la primera mitad del XIX, el exilio funcionaba como instrumento de regulación política y como forma de evitar el desangramiento de las elites y la reproducción de una lógica de guerra civil permanente. Las transformaciones de las comunicaciones a lo largo del siglo XX y la gravitación adquirida por la esfera pública internacional como caja de resonancia/y de reimpulso de la actividad política de los exiliados, incidieron en la funcionalidad de ciertas instituciones decimonónicas ("opción") e impactaron en la lógica de los actores estatales. Así los militares argentinos asumieron que la "guerra contra la subversión" no reconocía fronteras territoriales y que la libertad de quienes promovían "ideas disolventes" debía ser regulada, restringida o anulada. Veáse: SZNADJER, Mario y RONIGER, Luis. La política del destierro y el exilio en América Latina, México: FCE, 2013.

${ }^{55}$ Sobre la compleja maraña de decretos, actas y leyes referidas al derecho de opción bajo imperio del estado de sitio, véase nota 6 del Capítulo "El derecho a la libertad" del Informe de la visita de la CIDH de la OEA a la Argentina, 1980. Disponible en: http://desaparecidos.org/nuncamas/web/document/internac/cidh79/04.htm\#C.Derecho de opción para salir del país.
} 
una mera petición. ${ }^{56}$ Asimismo, operó prohibiendo y penalizando el retorno de los opcionados salvo autorización del Poder Ejecutivo. Todo esto en consonancia con la estrategia represiva dominante durante el "Proceso de Reorganización Nacional" (violencia criminal) y desde la convicción de las autoridades castrenses que salida del país de opositores políticos no sólo podría tener consecuencias en términos del cerco internacional $-\mathrm{y}$ desde lo que la Junta calificaba como "difamar", "crear patrañas contra la Argentina" o promover "campañas antiargentinas" -, sino desde el fortalecimiento de la oposición. La Junta entendía los presos opcionados podían usar el exilio como retaguardia, donde rearmarse y volver a la "guerra" (contraofensivas).

Si bien la Junta Militar no innovó en lo fundamental en la lógica que subyacía a las políticas de restricción y reglamentación del derecho de "opción" puestos en práctica desde abril de 1975 y hasta el 11 marco de 1976 - en una línea de expansión represiva que partiendo de la limitación en su aplicación (decreto 807, BORA 7/4/1975) y pasando por la prohibición a que sus beneficiarios permanecieran en el continente americano (decreto 642 BORA, 17/2/1976) y que llegó a convertirlo en pena de destierro porque criminalizaba el retorno de los "opcionados" (decreto 908 BORA, 17/3/1976) -; lo cierto es que en un contexto de cárceles pobladas por miles de presos políticos que sufrían la rigurosidad de las condiciones de encierro y estaban sometidos a la ley de fugas -; la "opción" pasó a ser una de las cifras del Estado de excepción. ${ }^{57}$ Aquel donde el poder omnímodo es capaz de mover incluso los límites de lo anormal,

${ }^{56}$ Decía Carlos Brocato: ¿Qué otra cosa que destierro ordenado ha sido el artilugio leguleyo con que la dictadura transformó la "opción para salir del país" bajo Estado de sitio? Curiosa opción la que quedó después: el que optaba era el Poder Ejecutivo. Primero confinaba al reo de un modo singular en una institución carcelaria, en un campo de concentración clandestino o en un mero y tenebroso 'chupadero'. Como se ve, este peculiarísimo Poder Ejecutivo-Dictadura se autoconfería opciones varias. Podía mantenerlas o cambiarlas, u otorgar la gracia de que el sospechoso se marchara a perpetuidad del país, porque perpetuo era el estado de sitio". BROCATO, Carlos. El exilio es nuestro. Buenos Aires: Sudamericana-Planeta, 1986, p. 74.

${ }^{57}$ Sugerimos atender a la especial preocupación del gobierno militar por la "opción, consultando las Actas Secretas de la Junta Militar encontradas en el Edificio Cóndor. Disponible en: http://www-archivosabiertos.com/ 
para inscribir jurídica o fácticamente otras excepciones (métodos ilegales y prácticas clandestinas). ${ }^{58}$

La ambigüedad de la institución de la "opción" y el uso discrecional que hizo de ella la Junta militar, enfrentó a los exiliados a una nueva disyuntiva en la denuncia. Si por una parte, la suspensión de la "opción" los orientó a luchar por su restablecimiento, efectivización plena y agilización ${ }^{59}$; por la otra, comprendieron que mientras la "opción" servía a la Junta para mostrar interna e internacionalmente que los militares respetaban la Constitución Nacional, en la práctica ese derecho constitucional devenía una forma de destierro institucionalizado. Para quienes estaban presos sin causa ni proceso y aún para quienes el Poder Ejecutivo evaluaba como ciudadanos que no constituían un "peligro" para para "la paz y la seguridad de la Nación" ${ }^{60}$, el derecho a recuperar la libertad plena e inmediata no fue tal. A lo sumo podían acogerse a solicitar la libertad vigilada o a peticionar - muchas veces de manera infructuosa -su salida del país. ${ }^{61}$ En tal sentido, la "opción" se tornó un "destierro ordenado" que desnudaba el poder omnímodo y arbitrario que concentró la Junta. Como denunciaba Hipólito Solari Yrigoyen desde

${ }^{58}$ En los últimos años, la producción académica ha comenzado a interesarse por la reconstrucción sistemática de las articulaciones entre detenciones (legales-ilegales) y exilios (expulsiones, "opciones", salidas requeridas, etc.). Entre los trabajos centrados en presos políticos opcionados y sobre la imbricación de las faces legal y clandestina de la represión, véase VAN MEERVENNE, Michel. Buscar refugio en un lugar desconocido. El exilio argentino en Bélgica (1973-1983). Buenos Aires: UNSAM, 2016. Tesis de maestría inédita. PISARELLO, Virginia. Los presos políticos de la última dictadura y la opción del exilio. El caso de la cárcel de Coronda. En: JENSEN, S. y LASTRA, S (edits.). Exilios: militancia y represión Nuevas fuentes y nuevos abordajes de los destierros de la Argentina de los años setenta. La Plata: EDULP, 2014, pp. 283307.

${ }^{59}$ CADHU, ob cit, 2014, p. 40.

${ }^{60}$ Sobre la dinámica dictatorial en concesión de la "opción", véase Los Decretos Secretos y Reservados del Poder Ejecutivo correspondientes al periodo 1976-1983. Disponibles en: https://www.boletinoficial.gob.ar/\#!extras/38

${ }^{61}$ La Asamblea permanente de Derechos Humanos de Buenos Aires elaboró en 1977 un informe en el que señalaba que el artículo 23 de la Constitución Nacional "no tolera cortapisa ni reglamentación alguna, dado que el Estado decide suspender las garantías constitucionales pero no los derechos fundamentales". Sin embargo, la Junta primero suspendió el derecho de "opción" y luego lo reglamentó introduciendo una enorme distorsión jurídica que instituyó una fórmula "tramposa" e "ilusoria", disponible sólo para las "familias pudientes" y limitada a la "discrecionalidad" del omnímodo Poder Ejecutivo. En este contexto tan poco auspicioso y a pesar de las dudas y con las prevenciones del caso, la APDH se inclinaba por "no desdeñar su utilización”. APDH. Consejo de Presidencia. Despacho de la comisión $n^{o} 1$ sobre derecho de opción, 30/11/1977. 
su exilio parisino, los "opcionados" tenían vedado legalmente el retorno hasta el levantamiento del Estado de sitio y por lo tanto eran candidatos a cometer un "delito de regreso ilegítimo" 62 .

\section{¿En qué medida la apelación al Derecho era una vía eficaz de búsqueda de verdad, libertad y justicia (punitiva)?}

La denuncia exiliar de la nueva institucionalidad implantada por las fuerzas de las armas contempló con especial atención no sólo las garantías procesales conculcadas por los militares (asistencia jurídica y defensa en juicio, proceso justo en tribunales imparciales y ante jueces naturales, presunción de inocencia, no retroactividad de las normas penales, presunción de inocencia), sino también el funcionamiento real del Poder Judicial, el comportamiento de los jueces de la Corte Suprema y de los tribunales inferiores ante la denuncia de violaciones a los DDHH y las dificultades que enfrentaban los abogados defensores de presos políticos y gremiales. ${ }^{63}$ En el ámbito doméstico, los exiliados asumieron el desafío de utilizar - pese a su vaciamiento y perversión -las instituciones de la "justicia burguesa" exigiendo la aplicación estricta de los instrumentos jurídicos disponibles para la protección de los derechos a la vida, la integridad física, la libertad y la verdad ( "opción", amparo, habeas corpus $^{64}$ ). Pero al mismo tiempo,

${ }^{62}$ PARCERO, Daniel et al. La Argentina exiliada. Buenos Aires: CEAL, 1985, p. 137.

${ }^{63}$ En el Coloquio Internacional sobre Desaparición Forzada de Personas celebrado en París en 1981, Roberto Bergalli (criminólogo argentino exiliado en Barcelona) recurría al informe de la CIDH para denunciar que en su país se violaba "el derecho de justicia y proceso regular en razón de las limitaciones que encuentra el Poder Judicial para el ejercicio de sus funciones, de la falta de las debidas garantías en los tribunales militares y de la ineficacia que en la práctica y en general, ha demostrado tener en Argentina el recurso de habeas corpus." Testimonio Latinoamericano, Barcelona, enero/febrero 1981, $\mathrm{n}^{\circ}$ 6, p. 16.

${ }^{64}$ En el Coloquio de París, COSOFAM explicaba que el sentido del habeas corpus de permitir localizar a aquellas personas detenidas por los poderes públicos era pervertido por el comportamiento de los jueces, que decían ignorar quiénes eran los autores de los secuestros, 
exploraron otras formas del Derecho (Derecho Internacional Humanitario) y otros ámbitos jurídicos y no sólo para la búsqueda de verdad y respeto del debido proceso, sino incluso imaginando a la justicia como territorio donde dirimir responsabilidades penales.

En este contexto, mientras los exiliados denunciaban que la Constitución Nacional se había convertido después del 24 de marzo de 1976 en mera referencia formal, continuaron propiciando que víctimas y familiares apelaran a ella e incluso a la normativa de excepción que la Junta promovió, de cara a intentar conseguir la libertad de los detenidos sin causas ni proceso, la mejora de las condiciones de detención de los presos legales o la localización de los que se encontraban en situación de desaparición. Así, en la Navidad de 1977, COSOFAM Madrid en solidaridad con los Familiares de Argentina recurría al pueblo y a las instituciones del Estado español para fortalecer su reclamo a la Junta militar de una "Navidad en Paz" consecuencia de una "Navidad con Justicia". En el petitorio reclamaba por "la aparición de los desaparecidos y la liberación de los detenidos por razones políticas sin causa ni proceso y/o la opción para salir del país", pero también por "el juzgamiento de los detenidos que tuvieran causa y /o proceso de acuerdo a la Constitución Nacional y a las leyes". ${ }^{65}$

En paralelo al uso crítico de las leyes y de la justicia doméstica, los exiliados apelaron a los instrumentos internacionales humanitarios generales $\mathrm{y}$ específicos $\mathrm{y}$ a las principales organizaciones de ámbito internacional o regional (NNUU, OEA), primero con la intención de denunciar la desprotección jurídica que se

negándose a continuar las investigaciones porque "esto ya no es de su competencia" (COSOFAM Buenos Aires. La búsqueda de los detenidos-desaparecidos en Argentina”. En: AMORÓS, ob cit, 2011, p. 214). En la misma línea, en agosto de 1981, la CADHU denunciaba ante la Comisión de DDHH de NNUU que el comportamiento de las autoridades castrenses "intimidando" y a la vez "dando esperanza a los familiares sobre la aparición de las víctimas si hay un reintegro silencioso a sus hogares", hizo que éstos se abstuvieran de "presentar denuncias e interponer recursos de habeas corpus, remedio judicial absolutamente enervado en su eficacia pero que cumple fines registrales del número de víctimas". CADHU. La violación sistemática de los derechos humanos persiste en la república Argentina, Ginebra, agosto 1981. En: AMORÓS, ob cit, 2011, p. 412.

${ }^{65}$ COSOFAM Madrid. La paz se construye con la justicia, diciembre 1977. En. AMORÓS, ob cit, 2011, p. 126. 
vivía en la Argentina ${ }^{66}$; y desde el mediodía del "Proceso de Reorganización Nacional (1979-1981), en búsqueda de un horizonte de justicia punitiva. En ese contexto, fue habitual que los exiliados recurrieran a la Declaración Americana de Derechos y Deberes del Hombre para denunciar la vulneración del derecho de justicia (Art XVIII) y al proceso regular (Art XXVI) o a la Convención Americana sobre Derechos Humanos para criticar el incumplimiento de principios y garantías procesales básicas, a saber: la no retroactividad de las normas penales, la aplicación de la ley penal más benévola, la presunción de inocencia, el derecho a un juicio imparcial y por tribunales competentes e independientes y el derecho a la asistencia profesional y técnica del reo (Arts. 8 y 9).

$\mathrm{Si}$ bien dudaban que la eficacia de los instrumentos internacionales humanitarios pudiera ir más allá de una condena política o moral al país; su uso respondió a la necesidad de traducir la situación interna a escala global $^{67}$, de multiplicar la solidaridad internacional y de avanzar por la vía de la justicia buscando los resquicios que les permitieran que las condenas no quedaran reducidas a gestos políticos contra el Estado, sino que derivaran en alguna forma de persecución y castigo de los individuos comprometidos en la violación de los DDHH en su país. En este contexto, los exiliados por un lado, exploraron las posibilidades que ofrecía el espacio público internacional y apelaron a su vigente arsenal normativo para exigir protección jurídica frente a las violaciones DDHH; y, por el otro, avanzaron para que sea desde la utilización de las Convenciones de Ginebra de 1949 y sobre Imprescriptibilidad de Crímenes de Guerra y contra la Humanidad (1968) o desde la elaboración de nuevos instrumentos jurídicos (algún tipo de Convención Internacional sobre Desaparición Forzada

\footnotetext{
${ }^{66}$ En Argentina. Proceso al Genocidio, la CADHU se asumía como la parte acusadora por las "violaciones graves, masivas, sistemáticas y persistentes de los derechos humanos, civiles, económicos y sociales" que estaba perpetrando la Junta Militar. (CADHU, ob cit, 2014, p. 173).

${ }^{67}$ En esta línea cabe entender la atención brindada tempranamente a la agresión contra asilados y refugiados instalados en la Argentina. Siguiendo la senda abierta por Chile, los exiliados argentinos convirtieron a asilados y refugiados en cifra del Estado terrorista y la forma más idónea de mostrar que lo que ocurría en Argentina era una afrenta contra la comunidad internacional toda y por lo tanto un crimen internacional. Sobre Chile, véase: BASTÍAS SAAVEDRA, Manuel. Sociedad civil en dictadura. Relaciones transnacionales, organizaciones y socialización política en Chile (1973-1993). Santiago de Chile: Ediciones Santiago Alberto Hurtado, 2013.
} 
de Personas) fuera posible perseguir más temprano que tarde a los responsables del delito más aberrante del gobierno dictatorial argentino: la desaparición forzada de personas.

Mientras en Argentina se multiplicaban los gestos políticos y normativos que apuntaban a que los militares pretendían cerrar (sin verdad ni justicia) el "problema de los desaparecidos" 68 , los exiliados de Argentina ${ }^{69}$ y de otros países latinoamericanos junto con familiares de víctimas y representantes del amplio espectro de organizaciones humanitarias de ámbito nacional y transnacional ${ }^{70}$, más varios juristas de gran trayectoria en el Derecho Penal e Internacional Humanitario ${ }^{71}$ movilizaron varios eventos internacionales ${ }^{72}$ que hicieron visible la posibilidad de usar o crear instrumentos jurídicos para enfrentar a las dictaduras de la Doctrina de la Seguridad Nacional y en un futuro juzgar penalmente a los culpables de violaciones a los Derechos Humanos.

De este modo, entre 1979 y 1981 , la relación de los exiliados con el universo de lo jurídico-legal comenzó a transitar por nuevos territorios. Mucho antes que la caída de la dictadura argentina

\footnotetext{
${ }^{68}$ Me refiero a la aprobación de las leyes de "desaparecidos" (22.062 y 22.068). Para un análisis más acabado del contexto político nacional e internacional, véase: JENSEN, Silvina. Los exiliados argentinos y la Justicia. Desde la denuncia de la vulneración del derecho al debido proceso a la lucha por un "Núremberg" (1976-1981). VIII Jornadas de trabajo sobre Historia Reciente, Rosario, UNR, Facultad de Arte y Humanidades, 10-12 agosto de 2016b. Inédito.

${ }^{69}$ En particular aquellos que hicieron del derecho y de su práctica profesional la forma de hacer efectiva su militancia humanitaria en el destierro: entre otros, Rodolfo Mattarollo, Eduardo Duhalde, vinculados a la CADHU y Roberto Bergalli y Enrique Bacigalupo.

${ }^{70}$ Entre otras el Servicio de Paz y Justicia, la Asamblea Permanente por los Derechos Humanos, la Liga Argentina de Derechos Humanos, la Comisión de Familiares de Desaparecidos, las Madres de Plaza de Mayo y el Centro de Estudios legales y Sociales de Argentina; la Asociación Internacional de Juristas Democráticos, el Centro Internacional para la Independencia de Jueces y Abogados, la Comisión Internacional de Juristas, la Federación Internacional de Derechos Humanos, el Movimiento Internacional de Juristas Católicos, la Unión Internacional de Abogados, Acción de los Cristianos para la Abolición de la Tortura, la Asociación Francesa de Paz y Justicia, Comité Católico contra el Hambre y por el Desarrollo y el Instituto de Derechos Humanos del Foro de París, entre otras.

71 Por ejemplo, Louis Joinet, integrante de la Subcomisión de Prevención de Discriminaciones y Protección de las Minorías de la Comisión de Derechos Humanos de NNUU; Héctor Faúndez Ledesma, Edmond Pettiti o Victoria Abellán, autores de proyectos de Convención sobre Desaparición Forzada debatidos por los exiliados argentinos.

${ }^{72}$ Entre otros, el I Coloquio Internacional sobre Desaparición Forzada de Personas de París (enero 1981), el I y II Congresos Latinoamericanos de Familiares de Detenidos Desaparecidos (San José de Costa Rica y Caracas, enero y noviembre de 1981) y el III Congreso de FEDEFAM (Caracas, junio 1982).
} 
estuviera cercana y cuando la forma de la salida del régimen militar resultaba difícil de precisar, desde el exilio empezaron a ser debatidas cuestiones que serían piedras angulares de la transición democrática. A saber, 1. ¿Cómo punir a los responsables de un delito cometido en la clandestinidad y cuya responsabilidad era sistemáticamente negada por los agentes estatales?; 2. ¿Qué tipo de delito eran las desapariciones forzadas y qué implicaba en términos de persecución penal definirlo como crimen contra la Humanidad y crimen internacional de acción continuada, y por tanto imprescriptible?, 3. ¿Cómo podía aplicarse la jurisdicción penal universal nacida en Núremberg a la persecución de los culpables de desapariciones forzadas en Argentina?; 4. ¿Qué valor tenía trabajar en la articulación de un instrumento jurídico nuevo como la Convención internacional de desaparición forzada para el caso de una dictadura que venía operando clandestinamente desde 1976?; 5. ¿En qué medida el caso argentino sólo habilitaba el uso de los actuales marcos normativos del Derecho Internacional o de la legislación penal del país, para no caer en una aplicación retroactiva de la ley y para evitar hacer de la justicia el territorio de los vencedores?; 6. ¿Cuáles eran los tribunales más idóneos para el juzgamiento de los responsables de las detencionesdesapariciones?, ¿los tribunales argentinos de un futuro gobierno electo por el pueblo, un tribunal internacional ad hoc como los de Núremberg o Tokio, una corte penal internacional a constituirse en el futuro $?^{73}$

\section{A manera de cierre}

Este trabajo pretendió incidir en un territorio poco explorado de la historiografía del último exilio político argentino, intentando mostrar cómo la acción colectiva de los desterrados del "Proceso de Reorganización Nacional" interpeló lo jurídico-legal, sea en la pretensión de denunciarlo y/o de utilizarlo a pesar de su perversión en

\footnotetext{
73 Algunos de estos debates pueden leerse en FundaLatin. Los desaparecidos. Propuestas para un proyecto de Convención Internacional contra las desapariciones forzadas. Caracas, 1982
} 
un intento desesperado por proteger los derechos humanos violados sistemáticamente por el Estado (sus aparatos y agentes vinculados); sea en la pretensión de expandirlo desde la apelación al Derecho Penal e Internacional Humanitario y desde la elaboración de nuevos instrumentos de prosecución de los responsables de aquel delito que se constituyó en la seña de identidad de la dictadura argentina: la desaparición forzada de personas.

El artículo hace foco sobre todo en los dilemas de la estrategia jurídica de los exiliados, que no fueron ajenos a la paradoja de una dictadura que operó punitivamente creando espacios de violencia inusitada, por fuera de todo control legal y desde la práctica clandestina; pero a la vez se presentó como uno de los órdenes más legalistas de la historia argentina, mantuvo formalmente la Constitución Nacional y a la vez se abocó a una frenética producción de una pseudojuricidad represiva pensada para servir a la "guerra contra la subversión" y para multiplicar sus posibilidades de enfrentar/retardar las impugnaciones, críticas y resistencias internas y externas.

En ese contexto, el primer dilema de la resistencia exiliar fue asumir que aunque la dictadura argentina procedía represivamente sobre todo de modo extrajudicial, clandestino y extremadamente violento, era importante desnudar la funcionalidad de su ropaje legal en tanto filtro disimulador de la violencia, expresión de la ideología de la Junta y su política de dominación y como amparo normativo incluso del accionar clandestino del Estado.

Del mismo modo, los exiliados asumieron que aunque el Estado negaba la existencia de perseguidos políticos y apenas admitía la presencia de "subversivos" huidos al exterior y de argentinos que habían optado por salir del país tal como estipulaba la Constitución; la persecución y represión (legal/ilegal) sobre asilados y refugiados latinoamericanos y el vaciamiento del sentido del derecho de "opción" eran suficientes para desvelar al mundo la verdadera naturaleza de la dictadura argentina.

Por último, en algunos casos reevaluando sus propias convicciones acerca del valor de la "justicia burguesa" y con enormes dudas tanto acerca de la eficacia del uso de instituciones como el habeas corpus, el amparo o la "opción" (en el ámbito argentino), como del impacto de los instrumentos e instituciones humanitarios del 
espacio internacional; los exiliados ensayaron diferentes estrategias jurídicas que interpelaron tanto a las instituciones del país, como a las del mundo y en el mediodía del "Proceso" incluso comenzaron a pergeñar un futuro "Núremberg" en el que fueran tramitadas las violaciones a los derechos humanos que se estaban produciendo en el país.

Por todo esto, podemos concluir que si las relaciones entre los exiliados y la ley no fueron sencillas, no por ello dejaron de tener intensidad y potencial en la denuncia de la dictadura.

RECEBIDO EM: 31/08/2016

APROVADO EM: 20/10/2016 